\title{
Effectiveness of re-education based on appropriate care methods using welfare equipment on the prevention of low back pain among care workers: a 1.5 year follow-up study
}

\author{
Kazuyuki IWAKIRI $^{1 *}$, Midori SOTOYAMA ${ }^{1}$, Masaya TAKAHASHI ${ }^{1}$, \\ Xinxin LIU ${ }^{1}$, Shigeki KODA ${ }^{1}$ and Kiyoshi ICHIKAWA ${ }^{2}$ \\ ${ }^{1}$ National Institute of Occupational Safety and Health, Japan \\ ${ }^{2}$ Welfare Technology Research Institute Corporation, Japan \\ Received October 6, 2017 and accepted May 30, 2018 \\ Published online in J-STAGE June 15, 2018
}

\begin{abstract}
Many care workers at elderly care facilities in Japan suffer occupational low back pain (LBP) despite the utilization of welfare equipment. When introducing welfare equipment such as hoists and sliding boards, education on appropriate care methods using welfare equipment is usually conducted, but the effect of education diminishes with time. This intervention study aimed to examine the effect of re-education on appropriate care methods using welfare equipment on the prevention of care workers' LBP at an elderly care facility. At the intervention facility, 49 care workers were enrolled in ergonomic education program for $1.5 \mathrm{yr}$ in order to improve care methods using welfare equipment. At the non-intervention facility, 33 care workers were not enrolled in the program. Rates of severe LBP were not significantly different between the facilities. However, during the study period, the rate of severe LBP among care workers did not increase at the intervention facility, while it doubled among care workers at the non-intervention facility. The care workers at the intervention facility showed improvement in care methods using welfare equipment during the study period. Hence, we think that re-education regarding appropriate care methods using welfare equipment has the potential to prevent exacerbation of LBP.
\end{abstract}

Key words: Intervention study, Re-education, Care worker, Low back pain (LBP), Welfare equipment

\section{Introduction}

Welfare equipment, such as hoists, sliding boards and sliding sheets, is useful for preventing occupational low back pain (LBP) among care workers working in care facilities ${ }^{1-6)}$. However, many care workers at elderly care

\footnotetext{
*To whom correspondence should be addressed.

E-mail: iwakiri@h.jniosh.johas.go.jp
}

(C)2018 National Institute of Occupational Safety and Health facilities in Japan suffer occupational LBP despite the utilization of welfare equipment ${ }^{7)}$. This is probably because they are not adopting appropriate care methods when they use welfare equipment. When introducing welfare equipment, education on appropriate care methods using the equipment is usually conducted for care workers. However, the effect of education diminishes with time, and care workers do not have sufficient knowledge regarding care methods using welfare equipment. Even though a lot of welfare equipment have been introduced to care facilities, LBP among care workers cannot be prevented unless 


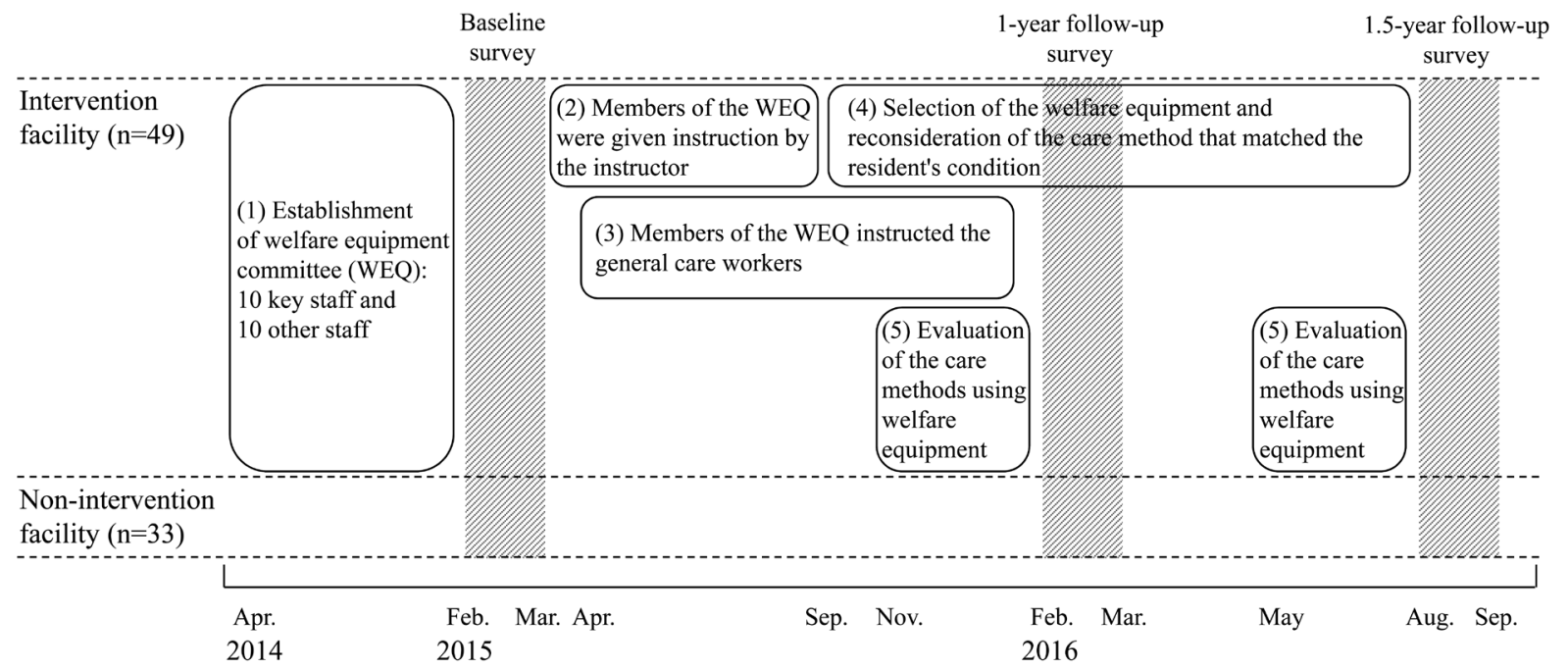

Fig. 1. Schedule of the ergonomic education program.

they properly use the equipment ${ }^{7,8}$. Thus, this study aimed to investigate the effects of re-education regarding appropriate care methods using welfare equipment on the prevention of care workers' LBP at an elderly care facility.

\section{Methods}

\section{Study design}

The study was conducted at two elderly long-term care facilities that had already introduced welfare equipment and had trained care workers in the use of the welfare equipment. One care facility served as the intervention facility, and the other served as the non-intervention facility. The intervention facility was a multi-unit facility with approximately 10 individual rooms and a shared space, while the non-intervention facility was a multi-bedroom facility. All care workers working at both facilities were included in this study. Questionnaires were distributed to the administrators and care workers before (baseline), $1 \mathrm{yr}$ after, and $1.5 \mathrm{yr}$ after the start of the intervention. The care workers who responded to all three questionnaires were included as the participants of this study; however, those who omitted their gender and age from the questionnaire were excluded. Questionnaires for the baseline survey were distributed from February to March 2015, questionnaires for the $1 \mathrm{yr}$ follow-up survey were distributed from February to March 2016, and questionnaires for the $1.5 \mathrm{yr}$ follow-up survey were distributed from August to September 2016.

Regarding ethical considerations, the administrators and care workers were well-informed about the study plan, and personal information given verbally or in writing was protected prior to obtaining subjects' written consent. This study was approved by the Ethics Board of the National Institute of Occupational Safety and Health of Japan, and it has been registered as ID H2704.

\section{Questionnaires}

The questionnaire given to the administrators collected basic information about the care facilities, the numbers and types of welfare equipment, and occupational safety and health management. The questionnaire administered to care workers collected basic characteristics, the severity of LBP in the last week, occupational safety and health activities, care methods, usage of welfare equipment, and job stressors. The severity of LBP was divided into four grades, based on a scheme devised by Von Korff et $a l .{ }^{9}$ : grade 0 (no LBP), grade 1 (LBP not interfering with work), grade 2 (LBP interfering with work), and grade 3 (LBP interfering with work and leading to sick-leave). Of these, grades 0 and 1 were defined as non-severe LBP, while grades 2 and 3 were defined as severe LBP. Questions regarding job stressors were constructed based on the job demand, job control, and worksite social support items of the brief job stress questionnaire ${ }^{10)}$.

\section{Ergonomic education program}

The intervention facility conducted an ergonomic education program on appropriate care methods using welfare equipment, in which the care workers were instructed on the proper use of welfare equipment after the baseline survey. The non-intervention facility did not conduct the program. The ergonomic education program recommended 
Table 1. Basic information about the care facilities and welfare equipment

\begin{tabular}{|c|c|c|c|c|c|c|}
\hline \multirow[b]{2}{*}{$\mathrm{n}$} & \multicolumn{3}{|c|}{ Intervention facility } & \multicolumn{3}{|c|}{ Non-intervention facility } \\
\hline & Baseline & $\begin{array}{c}1-y r \\
\text { follow-up }\end{array}$ & $\begin{array}{c}1.5-\mathrm{yr} \\
\text { follow-up }\end{array}$ & Baseline & $\begin{array}{c}1-y r \\
\text { follow-up }\end{array}$ & $\begin{array}{c}1.5-y r \\
\text { follow-up }\end{array}$ \\
\hline \multicolumn{7}{|l|}{ Basic information of care facilities } \\
\hline Care workers & 91 & 105 & 128 & 72 & 74 & 75 \\
\hline Residents in a care facility & 175 & 220 & 220 & 163 & 161 & 162 \\
\hline Needing care level in residents (between 1 and 5) & 3.9 & 3.8 & 3.9 & 3.9 & 4.1 & 3.9 \\
\hline Retired care workers during the previous year & 8 & 12 & 20 & 3 & 4 & 5 \\
\hline Absent care workers during the previous year & 0 & 0 & 1 & 2 & 1 & 2 \\
\hline \multicolumn{7}{|l|}{ Welfare equipment } \\
\hline Mobile hoist & 22 & 24 & 26 & 0 & 0 & 0 \\
\hline Rail guide hoist in bathrooms & 2 & 3 & 3 & 2 & 2 & 2 \\
\hline Stationary hoist in bathrooms & 18 & 12 & 18 & 0 & 0 & 0 \\
\hline Automatic bathing equipment & 3 & 3 & 3 & 2 & 2 & 2 \\
\hline Sliding board & 4 & 5 & 5 & 1 & 4 & 4 \\
\hline Sliding sheet & 23 & 43 & 148 & 0 & 0 & 3 \\
\hline Powered adjustable bed & 220 & 220 & 220 & 163 & 163 & 163 \\
\hline
\end{tabular}

the use of welfare equipment to the care workers, and an instructor educated them on the selection method, the proper usage of the welfare equipment, and the appropriate working posture. The instructor was a welfare equipment ergonomic expert. The schedule of the ergonomic education program is shown in Fig. 1. The main steps were:

(1) The administrator of the intervention facility established a welfare equipment committee (WEQ) and selected 10 key staff and 10 other staff as members before the baseline survey.

(2) The instructor instructed the 20 members of the WEQ on appropriate care methods using welfare equipment during the six months following the baseline survey.

(3) The 20 members of the WEQ instructed the general care workers on appropriate care methods using welfare equipment following the baseline survey until the $1 \mathrm{yr}$ follow-up survey.

(4) The key staff reconsidered the selection of welfare equipment and the care method that matched residents' conditions, together with the general care workers in charge of residents in the period between 6 months after the baseline and the $1.5 \mathrm{yr}$ follow-up surveys.

(5) The key staff members of the WEQ also evaluated the care methods using welfare equipment used by the general care workers. The evaluations were conducted in the three months prior to the $1 \mathrm{yr}$ follow-up and the $1.5 \mathrm{yr}$ follow-up surveys.

\section{Data analysis}

The $\chi^{2}$ test and unpaired $t$-test were used to compare differences between the facilities. The $\chi^{2}$ test was also used to compare differences between the care workers who were included in the analysis and those who dropped out of the study. The drop-out care workers included those who relocated to related facilities or who changed jobs. Questions regarding transfer and bathing methods were measured using a five-point scale which was dichotomized in the analysis using the same method as in a previous study ${ }^{7}$. Job demand and job control summarized three items into one and the range was 3 (low stressor) to 12 (high stressor). Worksite social support summarized six items into one and the range was 6 (low stressor) to 24 (high stressor). IBM SPSS version 22 was used for the statistical analysis.

\section{Results}

The questionnaires completed by the administrators were returned from their respective care facilities. The number of respondents to the questionnaires given to care workers was 101 (response rate, 93.8\%) at the intervention facility, and 64 (response rate, 86.3\%) at the non-intervention facility. Forty-nine care workers from the intervention facility and 33 from the non-intervention facility, who completed all three questionnaires, were included in the final analysis.

\section{Basic information about the care facilities and welfare equipment}

Table 1 shows the number of care workers and residents at the care facilities, the average of care level needs of residents, the number of retired and absent care work- 
Table 2. Basic characteristics of care workers at the baseline

\begin{tabular}{|c|c|c|c|}
\hline$\%$ or Mean $\pm \mathrm{SD}$ & $\begin{array}{l}\text { Intervention facility } \\
\qquad(\mathrm{n}=49)\end{array}$ & $\begin{array}{l}\text { Non-intervention facility } \\
\qquad(\mathrm{n}=33)\end{array}$ & $p$ \\
\hline \multicolumn{4}{|l|}{$\operatorname{Sex}(\%)$} \\
\hline Male & 38.8 & 48.5 & 0.50 \\
\hline Female & 61.2 & 51.5 & \\
\hline Age (yr) & $32.4 \pm 10.2$ & $40.2 \pm 9.9$ & 0.001 \\
\hline Height (cm) & $162.0 \pm 8.0$ & $164.9 \pm 9.6$ & 0.14 \\
\hline Body Mass Index (BMI) & $22.6 \pm 4.8$ & $23.0 \pm 2.9$ & 0.69 \\
\hline \multicolumn{4}{|l|}{ Smoke $(\%)$} \\
\hline Smoking & 12.2 & 48.5 & $<0.001$ \\
\hline No smoking & 77.6 & 42.4 & \\
\hline \multicolumn{4}{|l|}{ Qualification (multiple answers allowed; \%) } \\
\hline Certified care worker & 42.9 & 66.7 & 0.07 \\
\hline Care worker & 53.1 & 24.2 & 0.01 \\
\hline Nursing care manager & 2.0 & 3.0 & 1.00 \\
\hline No qualification & 10.2 & 6.1 & 0.70 \\
\hline \multicolumn{4}{|l|}{ Work time $(\%)$} \\
\hline Full-time & 83.7 & 84.8 & 1.00 \\
\hline Part-time & 16.3 & 15.2 & \\
\hline \multicolumn{4}{|l|}{ Work shift system (\%) } \\
\hline Day shift & 26.5 & 21.2 & $<0.001$ \\
\hline Two shifts & 2.0 & 42.4 & \\
\hline Three shifts & 71.4 & 30.3 & \\
\hline \multicolumn{4}{|l|}{ Total weekly working hours (\%) } \\
\hline$<35 \mathrm{~h}$ & 14.3 & 9.1 & 0.01 \\
\hline $35 \mathrm{~h} \leq,<40 \mathrm{~h}$ & 16.3 & 45.5 & \\
\hline $40 \mathrm{~h} \leq,<45 \mathrm{~h}$ & 38.8 & 36.4 & \\
\hline $45 \mathrm{~h} \leq$ & 30.6 & 6.1 & \\
\hline \multicolumn{4}{|l|}{ Job stressors } \\
\hline Job demand (between 3 and 12) & $9.0 \pm 2.0$ & $9.6 \pm 1.9$ & 0.18 \\
\hline Job control (between 3 and 12) & $7.4 \pm 1.6$ & $7.5 \pm 1.9$ & 0.87 \\
\hline Worksite social support (between 6 and 24) & $13.1 \pm 3.4$ & $12.8 \pm 3.4$ & 0.64 \\
\hline
\end{tabular}

$p$ : The $\chi^{2}$ test and $t$-tests were used to examine differences between the facilities.

ers during the previous year, and the numbers and types of welfare equipment. The care level needs of residents ranged from 1 to 5 , where level 1 is low and level 5 is very high. The average of care level needs of residents was 3.9 at the baseline and the $1.5 \mathrm{yr}$ follow-up surveys at both facilities. The total number of retired and absent care workers in the previous year had increased at the $1.5 \mathrm{yr}$ followup survey at both facilities. A lot of welfare equipment had been introduced at the intervention facility compared with the non-intervention facility. All rooms in both facilities were completely equipped with powered adjustable beds.

Medical checkup, health committee establishment, appointment with an industrial physician and health supervisor, training or instruction courses on care methods and usage of the welfare equipment, promotion of the use of welfare equipment, evaluation of the care methods and use of welfare equipment, and consultation on appropriate care method and use of welfare equipment with a person in charge were conducted in both facilities.

\section{Basic characteristics of care workers at the baseline}

Table 2 shows the basic characteristics of care workers at the baseline. Age, smoking, work shift system, and total weekly working hours were significantly different between the intervention facility and the non-intervention facility. At the non-intervention facility, the average age and smoking rate of care workers were high but weekly working hours were shorter than at the intervention facility. BMI and job stressors were not significantly different between the facilities. 
Table 3. Change of severe LBP within the same groups of care workers

\begin{tabular}{|c|c|c|c|c|c|c|}
\hline & & \multicolumn{2}{|c|}{$\begin{array}{c}\text { Intervention facility } \\
\qquad(\mathrm{n}=49)\end{array}$} & \multicolumn{2}{|c|}{$\begin{array}{l}\text { Non-intervention facility } \\
\qquad(\mathrm{n}=33)\end{array}$} & \multirow{2}{*}{$p$} \\
\hline & & $\mathrm{n}$ & $\%$ & $\mathrm{n}$ & $\%$ & \\
\hline \multicolumn{7}{|l|}{ Baseline $\rightarrow$ 1-yr follow-up } \\
\hline Non-severe LBP $\rightarrow$ Non-severe LBP : & No severe LBP & 39 & 79.6 & 22 & 66.7 & 0.69 \\
\hline Non-severe LBP $\rightarrow$ Severe LBP : & Getting worse & 3 & 6.1 & 3 & 9.1 & \\
\hline Severe LBP $\rightarrow$ Non-severe LBP : & Getting better & 4 & 8.2 & 2 & 6.1 & \\
\hline Severe LBP $\rightarrow$ Severe LBP : & Having severe LBP & 3 & 6.1 & 4 & 12.1 & \\
\hline \multicolumn{7}{|l|}{ Baseline $\rightarrow 1.5$-yr follow-up } \\
\hline Non-severe LBP $\rightarrow$ Non-severe LBP : & No severe LBP & 37 & 75.5 & 16 & 48.5 & 0.09 \\
\hline Non-severe LBP $\rightarrow$ Severe LBP : & Getting worse & 4 & 8.2 & 8 & 24.2 & \\
\hline Severe LBP $\rightarrow$ Non-severe LBP & Getting better & 2 & 4.1 & 2 & 6.1 & \\
\hline Severe LBP $\rightarrow$ Severe LBP : & Having severe LBP & 4 & 8.2 & 4 & 12.1 & \\
\hline
\end{tabular}

$p$ : The $\chi^{2}$ test was used to examine differences between the facilities.

\section{Severe low back pain (LBP)}

At the baseline, the rate of severe LBP was $14.3 \%$ and that of non-severe LBP was $85.7 \%$ among the care workers at the intervention facility, and the rate of severe LBP was $18.2 \%$ and that of non-severe LBP was $75.8 \%$ among the care workers at the non-intervention facility. The rates were not significantly different between the facilities at the baseline ( $p=0.55)$. At the $1 \mathrm{yr}$ follow-up, the rate of severe LBP was $12.2 \%$ and that of non-severe LBP was $87.8 \%$ among the care workers at the intervention facility, and the rate of severe LBP was $21.2 \%$ and that of non-severe LBP was $78.8 \%$ among care workers at the non-intervention facility. The rates were not significantly different between the facilities at the $1 \mathrm{yr}$ follow-up ( $p=0.36$ ). At the $1.5 \mathrm{yr}$ follow-up, the rate of severe LBP was $16.3 \%$ and that of non-severe LBP was $79.6 \%$ among care workers at the intervention facility, and the rate of severe LBP was $36.4 \%$ and that of non-severe LBP was $60.6 \%$ among the care workers at the non-intervention facility. The rates tended to be significantly different between the facilities at the $1.5 \mathrm{yr}$ follow-up $(p=0.06)$. Within the $1.5 \mathrm{yr}$ follow-up period, the rate of severe LBP doubled among the workers at the non-intervention facility.

Table 3 shows the changes in rates of severe LBP within the same groups of care workers from the baseline to the $1 \mathrm{yr}$ follow-up and the $1.5 \mathrm{yr}$ follow-up. The changes in the rates of severe LBP from the baseline to the $1 \mathrm{yr}$ follow-up were not significantly different between the facilities $(p=0.69)$. The changes in the rates of severe LBP from the baseline to the $1.5 \mathrm{yr}$ follow-up were not statistically significant between the facilities $(p=0.09$ ), but the number of care workers who did not have severe LBP decreased and the number of care workers with severe LBP increased during the study period at the non-intervention facility.

The rates of severe LBP among the care workers who dropped out after the baseline survey were not significantly different between the facilities. The rate of severe LBP of the dropout care workers was compared with those of the care workers who were included in the analysis in each survey of the two facilities. There was no significant difference between these care workers' rates of LBP in any of the surveys of the two facilities. In terms of BMI, smoking, and total weekly working hours, there were no differences between the dropout care workers and the care workers included in the final analysis.

\section{Occupational safety and health activities and care methods of the care workers}

Table 4 shows the occupational safety and health activities and care methods of the care workers. At the intervention facility, the activities and care methods that increased during the study period were: "Training or instruction courses on care methods," "Training or instruction courses on using welfare equipment," "Use of a sliding board or a sliding sheet in transfer," "Adjustment of the height and back support section of a bed in transfer," and "No lifting of residents by human power in bathing". At the nonintervention facility, however, these activities and care methods decreased during the study period, except for "Use of a sliding board or a sliding sheet in transfer". The care workers who used a sliding board or a sliding sheet in transfer increased but those who adjusted the height and back support section of a bed decreased at the nonintervention facility. Moreover, "Use of the manual for the care method," "Promoting discussion of care method improvements among colleagues," "No lifting of the resi- 


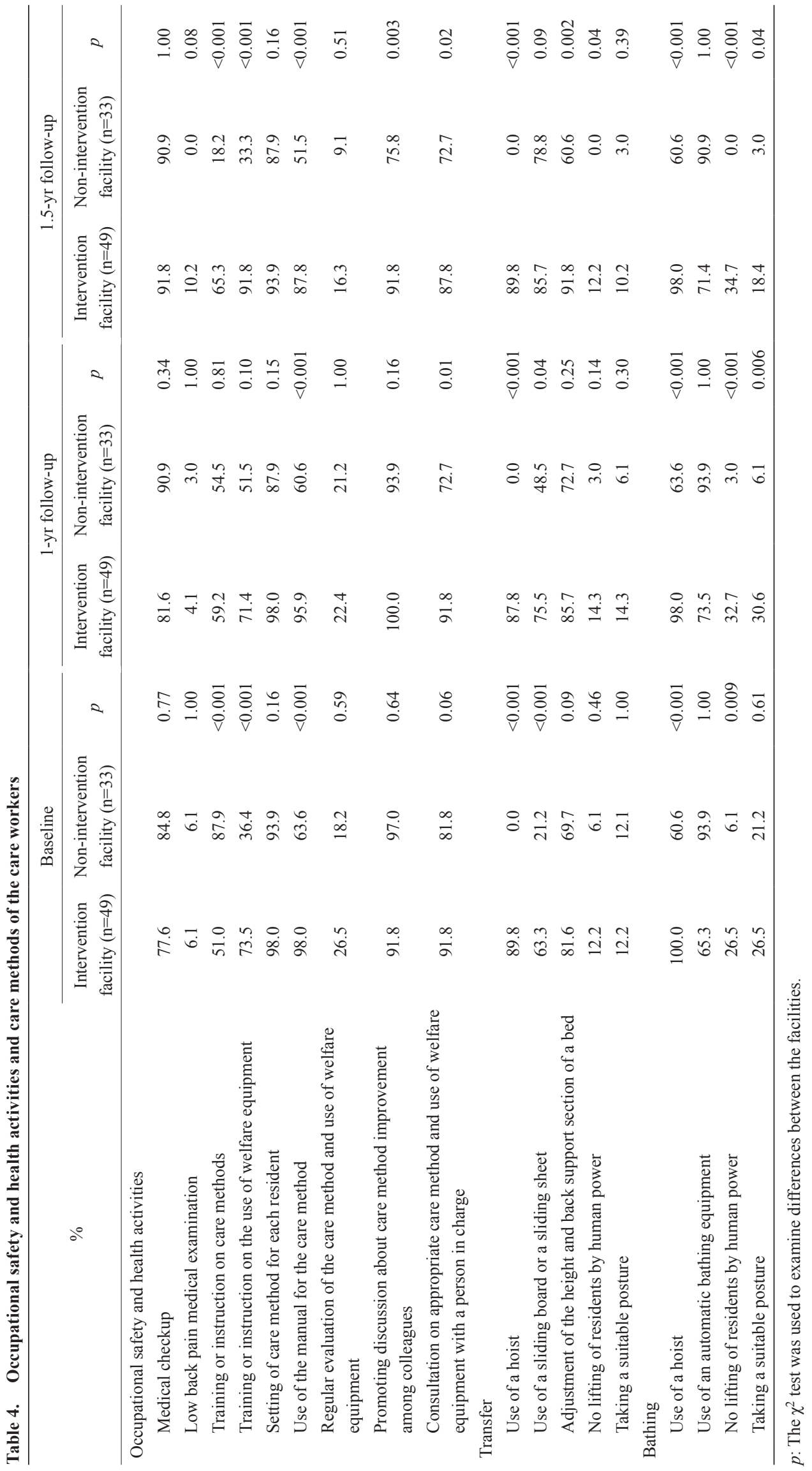


dent by human power in transfer," and "Taking a suitable posture in transfer or bathing" decreased during the study period at the non-intervention facility.

At both facilities, approximately $70 \%$ to $90 \%$ of care workers conducted "Medical checkup," "Establishment of the care method for each resident," "Promoting discussion of care method improvements among colleagues," and "Consultation on appropriate care methods and use of welfare equipment with a person in charge". The number of care workers who used a hoist and automatic bathing equipment in transfers and bathing did not change significantly during the study period at either facility.

\section{Discussion}

In this study, the rate of severe LBP among the care workers was not significantly different between the facilities. However, during the study period, the rate of severe LBP among care workers at the intervention facility did not increase, while it doubled among the care workers at the non-intervention facility. Previous studies have reported that the rates of care workers' LBP decreased after proper utilization of welfare equipment ${ }^{1-6)}$, and after conducting education programs appropriate care methods and working posture ${ }^{11-14)}$.

The two facilities were different in some respects at the baseline. However, the rates of severe LBP among the care workers were not significantly different between the facilities at the baseline. Thus, we focused on the relative changes in LBP at each facility. Even though the initial conditions were different between the facilities, we consider that the subsequent changes in working practice affected the rates of severe LBP among the care workers. From this perspective, the care workers who used a sliding board or a sheet in transfer increased during the study period at both facilities. The care workers who adjusted the height and back support section of beds increased at the intervention facility, but decreased at the non-intervention facility. The height and back support section of a bed must be adjusted in order to properly use a sliding board or a sheet in transfer. Therefore, our results suggest that the care workers at the non-intervention facility did not adjust the height and back support section of beds, when they used a sliding board or a sliding sheet.

Moreover, the number of care workers who received training and instruction courses on appropriate care methods using welfare equipment and who did not manually lift residents during bathing decreased at the nonintervention facility. On the other hand, the number of care workers receiving training and not manually lifting residents during bathing increased during the study period at the intervention facility. Even though a lot of welfare equipment such as hoists, sliding boards and sliding sheets have been increased to care facilities, severe LBP among care workers cannot be prevented unless the equipment is properly used ${ }^{7,8)}$. Therefore, we think that appropriate care methods and proper use of welfare equipment at the intervention facility suppressed the increase of severe LBP among their care workers. At the non-intervention facility, severe LBP among the care workers increased because these improvements were insufficiently implemented.

Since April 2015, elderly individuals with care needs scored 3 or more are the only persons eligible to be transferred to an elderly long-term care facility in Japan ${ }^{15}$. An elderly person categorized as care level 3 exhibits a dramatic impairment of activities of daily living and needs nearly full-scale nursing care. According to the interviews conducted with the administrators at both care facilities, caring for elderly persons with severe dementia and disability has increased the burden of care workers due to the change in the care needs level from 1 to 3 . We need to investigate this further, but it may be one of the factors behind the lack of decrease in the rate of severe LBP at the intervention facility.

A difference in the rates of severe LBP at the two facilities appeared at the $1.5 \mathrm{yr}$ follow-up, but did not appear at the $1 \mathrm{yr}$ follow-up. The time when the intervention effect appears depends on the content and the number of interventions $^{1-6,11-14)}$. However, the change in the care needs level of residents in 2015, rather than the content and the number of interventions might have influenced the timing of the appearance of the intervention effect. Although we need to investigate this further, we hypothesize that the effect of the change in the care needs level of residents was not initially apparent, rather it appeared a year or more later.

In this study the numbers of target facilities and care workers were small, and the facility type and the numbers and types of welfare equipment differed between facilities. Also, many of the initial conditions at the two facilities were different. Under these circumstances, the improvement process at each facility would be different. The results of this study include the influences of these differences between the two facilities. Hence, it will be necessary to conduct a large-scale study encompassing differences in facility type and the numbers and types of welfare equipment. In addition, an objective assessment will also be necessary in order to improve the reliability of 
the questionnaire survey.

In conclusion, the rate of severe LBP among care workers was not significantly different between the two facilities studied, but it did not increase during the study period at the intervention facility, whereas it doubled at the non-intervention facility. This shows that re-education regarding the appropriate care methods using welfare equipment may prevent an increase in LBP. If a large-scale study were conducted, severe LBP may be significantly different between the facilities. Unless appropriate education is continued, care workers' awareness of occupational safety and health will be lacking and their complaints of LBP may increase. Therefore, we think that continuous improvement efforts regarding care methods using welfare equipment have the potential to prevent the exacerbation of LBP among care workers.

\section{References}

1) Owen BD, Keene K, Olson S (2002) An ergonomic approach to reducing back/shoulder stress in hospital nursing personnel: a five year follow up. Int J Nurs Stud 39, 295-302. [Medline] [CrossRef]

2) Collins JW, Wolf L, Bell J, Evanoff B (2004) An evaluation of a "best practices" musculoskeletal injury prevention program in nursing homes. Inj Prev 10, 206-11. [Medline] [CrossRef]

3) Miller A, Engst C, Tate RB, Yassi A (2006) Evaluation of the effectiveness of portable ceiling lifts in a new long-term care facility. Appl Ergon 37, 377-85. [Medline] [CrossRef]

4) Garg A, Kapellusch JM (2012) Long-term efficacy of an ergonomics program that includes patient-handling devices on reducing musculoskeletal injuries to nursing personnel. Hum Factors 54, 608-25. [Medline] [CrossRef]

5) Gold JE, Punnett L Gore RJ, ProCare Research Team (2017) Predictors of low back pain in nursing home workers after implementation of a safe resident handling programme. Occup Environ Med 74, 389-95. [Medline] [CrossRef]

6) Iwakiri K, Matsudaira K, Ichikawa K, Takahashi M (2017) Effects of intervention program for systematic use of transfer equipment on care workers' low back pain in elderly care facilities. Sangyo Eiseigaku Zasshi 59, 82-92. [Medline] [CrossRef]
7) Iwakiri K, Takahashi M, Sotoyama M, Liu X, Koda S (2016) Low back pain among workers in care facilities for the elderly after introducing welfare equipment. Sangyo Eiseigaku Zasshi 58, 130-42. [Medline] [CrossRef]

8) Tomioka K, Higuchi Y, Shindo H (2007) A validation study of devices designed to reduce loads in provision of care: whether these assistive devices are used, or not, and whether work posture is appropriate or not. Sangyo Eiseigaku Zasshi 49, 113-21. [Medline] [CrossRef]

9) Von Korff M, Ormel J, Keefe FJ, Dworkin SF (1992) Grading the severity of chronic pain. Pain 50, 133-49. [Medline] [CrossRef]

10) Ando E, Kawakami N, Shimazu A, Shimomitsu T, Odagiri Y (2015) Reliability and validity of the English version of the New Brief Job Stress Questionnaire. Presented at the 31 st International Conference on Occupational Health. Seoul, Korea, 31 May-5 June 2015. The Brief Job Stress Questionnaire English version: http://www.mhlw. go.jp/bunya/roudoukijun/anzeneisei12/dl/160621-1.pdf. Accessed March 31, 2018.

11) Risør BW, Casper SD, Andersen LL, Sørensen J (2017) A multi-component patient-handling intervention improves attitudes and behaviors for safe patient handling and reduces aggression experienced by nursing staff: a controlled before-after study. Appl Ergon 60, 74-82. [Medline] [CrossRef]

12) Ree E, Lie SA, Eriksen HR, Malterud K, Indahl A, Samdal O, Harris A (2016) Reduction in sick leave by a workplace educational low back pain intervention: a cluster randomized controlled trial. Scand J Public Health 44, 571-9. [Medline] [CrossRef]

13) Ghadyani L, Tavafian SS, Kazemnejad A, Wagner J (2017) Effectiveness of multidisciplinary group-based intervention versus individual physiotherapy for improving chronic low back pain in nursing staff: a clinical trial with 3- and 6-month follow-up visits from Tehran, Iran. Asian Spine J 11, 396-404. [Medline] [CrossRef]

14) Shojaei S, Tavafian SS, Jamshidi AR, Wagner J (2017) A multidisciplinary workplace intervention for chronic low back pain among nursing assistants in Iran. Asian Spine J 11, 419-26. [Medline] [CrossRef]

15) Japan Ministry of Health, Labour and Welfare (2014) Revised long-term care insurance act (in Japanese). http:// www.mhlw.go.jp/file/06-Seisakujouhou-12300000Roukenkyoku/k2014.pdf. Accessed March 31, 2018. 